\title{
Variability in the number of mental foramina in the African green monkey (Grivet) (Chlorocebus aethiops)
}

\author{
Kamil Mrożek ${ }^{1,2} \oplus \cdot$ Justyna Marchewka ${ }^{3} \cdot$ Bartosz Leszczyński ${ }^{4} \cdot$ Andrzej Wróbel $^{4} \cdot$ Henryk Głąb $^{2}$
}

Received: 2 February 2020 / Revised: 2 March 2020 / Accepted: 7 March 2020 / Published online: 7 April 2020

(c) The Author(s) 2020

\begin{abstract}
This study aimed to determine the number of mental foramina (MFs) in vervet monkeys of the Cercopithecini tribe and perform a $\mu \mathrm{CT}$ analysis of mental foramina and mandibular canal morphology. A total of 19 simian skulls belonging to Chlorocebus aethiops species were used in the analyses. An average of three mental foramina was present in most individuals from the analyzed group. The Mann-Whitney test revealed no statistically significant difference between the number of foramina on the right- and left-hand side. Likewise, no statistically significant differences between the number of MFs across sexes were observed. Correlation coefficient values between mandibular length and the ipsilateral number of MF indicate a weak and statistically non-significant $(p>0.05)$ linear relationship. Volumetric reconstructions revealed the presence of a single periosteal sheathed mandibular canal terminated with four small mental foramina.
\end{abstract}

Keywords Mental foramina $\cdot$ Mandibular canal $\cdot$ Chlorocebus aethiops $\cdot$ Vervet monkey $\cdot$ Grivet $\cdot \mu C T$

\section{Introduction}

In human anatomy, the mental foramen is a bilateral opening located on the anterior surface of the mandible. It transmits the terminal branches of the inferior alveolar nerve and corresponding arteries and veins (Iwanaga et al. 2015, 2016). It is generally accepted that the mental nerve is known to have four branches (mental, medial inferior labial, lateral inferior labial and angular) after exiting the MF, which provides sensory innervation to specialized mechanoreceptors associated with the lower lip, lateral skin of the lower jaw and chin, as well as the buccal part of the gums (Iwanaga et al. 2015; Torres et al. 2015).

Kamil Mrożek

kamil.mrozek@uj.edu.pl

1 Nature Education Centre, Jagiellonian University, ul. Gronostajowa 5, 30-387 Krakow, Poland

2 Department of Anthropology, Institute of Zoology and Biomedical Research, Jagiellonian University, Krakow, Poland

3 Department of Human Biology, Institute of Biological Sciences, Cardinal Stefan Wyszynski University, Warszawa, Poland

4 Department of Medical Physics, Marian Smoluchowski Institute of Physics, Jagiellonian University, Krakow, Poland
In human anatomy, multiple craniofacial foramina usually are considered non-metric traits (Williams and Krovitz 2004); while in non-human primates, the multiplicity of some cranial foramina is rather common (Riesenfeld 1956; Ashton and Oxnard 1958; Msuya and Harrison 1994). According to Grzybowski (1927), a single mental foramen is usually observed in human hemimandibles. Kadanoff et al. (1970) showed differences in the number of mental foramina from absence to double or triple, equal or unequal size, close or widely separate, even multiple or in the form of a cluster. The morphology of the mental foramen varies depending on age (Gershenson et al. 1986), sex (Sawyer et al. 1998; Souaga et al. 2004) and ethnicity (Zivanovic 1970; Green 1987; Santini and Land 1990), as well as within the same race, in different geographical regions (Phillips et al. 1992; Lindh et al. 1995) and among residents of the same geographical area (Ari I Kafa et al. 2005). The body of publications on the multiplicity of the mental foramen in human anatomy is quite large, although such multiplicity itself is relatively rare: $0-14.3 \%$ (in different worldwide populations) (Hanihara and Ishida 2001).

Anatomical variation of the mental foramen (MF) has been reported in the literature, with a particular interest in the presence of additional foramina in the vicinity of the MF. Terms such as: accessory buccal foramina (Naitoh et al. 2009a), accessory mental foramina (Simonton 
1923; Riesenfeld 1956; Sisman et al. 2012), multiple mental foramina or accessory mandibular foramina (Patil et al. 2013), additional mental foramina (Santos et al. 2013), double mental foramina (Igarashi et al. 2004; von Arx et al. 2014) have been used to describe AMFs. Many authors defined the 'AMF' as any foramen in addition to the mental foramen (MF) in the lateral body of the mandible (Mraiwa et al. 2003; Prabodha and Nanayakkara 2006; Cagirankaya and Kansu 2008; Singh and Srivastav 2011; Thakur et al. 2011; Gupta and Soni 2012; Jha and Kumar 2012; Ahmed et al. 2014; Rai et al. 2014; Paraskevas et al. 2015). Some authors described the AMF as a small foramen in the area surrounding the MF (Riesenfeld 1956; Sutton 1974). Sisman et al. (2012) described AMFs in cone-beam computed tomographic (CBCT) images on each side of the mandible as foramina continuous with the mandibular canal, appearing smaller than the MF. Pancer et al. (2014) defined the AMF as being continuous both with the inferior alveolar canal and with the inferior alveolar nerve. Iwanaga et al. (2015) took into consideration the results of different imaging methods and formulated a definition of the AMF as "a foramen shown by CT to be continuous with the mandibular canal and smaller than the MF, regardless of whether nerves and/ or vessels arise from it".

Not only do non-human primates differ in the number of mental foramina but they also usually show significant variability in their size, shape, and position. Research conducted by Iwanaga et al. (2017) on the mandible of Macaca fascicularis yielded results similar to those in humans in terms of innervation. Some authors discussed variations in MF morphology as well as analyzed anteroposterior positions of the AMFs relative to the MF and its morphological shape in primates (Fukase 2014). However, in contrast to humans, the multiplicity of the mental foramen (MF) in non-human primates (NHP) is rather commonly observed, although there are disproportionately few literature reports on this subject (Simonton 1923; Harris 1927; Montagu 1954; Aitchison 1965; Swindler and Wood 1982; Robinson 2003; Iwanaga et al. 2017; Sunohara et al. 2017). According to Simonton (1923), 39\% of orangutans, $27 \%$ of gorillas and $15 \%$ of chimpanzees had AMFs. Swindler and Wood (1982) stated that Pan and Papio species have often multiple mental foramina. Iwanaga et al. (2017) reported that in the cynomolgus monkey (Macaca fascicularis), 9/10 sides had AMFs.

It has been suggested that separation of the mental nerve into several fasciculi earlier than the formation of the mental foramen until the 12th week of pregnancy could be a reason for the formation of an accessory mental foramen. (Toh et al. 1992; Katakami et al. 2008; Naitoh et al. 2009a; Iwanaga et al. 2015).
Due to the fact that the evolutionary changes occurring in the craniofacial region of the Primates are relatively new features, the analysis of such a monophyletic group is useful for organizing knowledge of its biological diversity or providing insight into events that occurred during the evolution of craniofacial traits.

The aim of the present study was to evaluate the variability in the number of mental foramina in the African green monkey (grivet) (Chlorocebus aethiops). The authors also performed an analysis of the number of MFs and examined the course of the mandibular canal by means of $\mu \mathrm{CT}$ imaging.

\section{Materials and methods}

A total of 19 skulls of monkeys belonging to Chlorocebus aethiops species were used in the analyses. The skulls were donated to the Anthropology Department of Jagiellonian University by the currently non-existent Vaccine Production Plant in Lublin, Poland, where sex was determined based on dimorphic features in individuals' lifetime and it was concluded that the group contained 10 males and 9 females.

The number of mental foramina was counted macroscopically and with the use of a magnifying glass. The authors studied the asymmetry in the number of mental foramina and the relationship between the number of MFs and the sex of the individuals. For the purpose of the study, it was assumed that the age of the animal had no significant effect on the number of mental foramina (Oliveira-Santos et al. 2011; Sisman et al. 2012). In this study, the authors decided to define the accessory mental foramina according to Naitoh et al. (2009a, 2011) and Sisman et al. (2012) who described AMFs in cone-beam computed tomographic (CBCT) images as foramina continuous with the mandibular canal, appearing smaller than the MF. Whereas, MF from AMFs was differentiated on the basis of the foramina surface measurements made using NRECON SkyScan software (version 1.6.5) recognizing foramen with the largest surface as MF and all others as AMFs. Examples of dry skulls of the analyzed species with a different numbers of accessory mental foramina are shown in Fig. 1.

To assess the correlation between the number of foramina and the length of the mandible, the maximal mandibular length measurements of all 19 skulls were made. Measurements were made using an electronic caliper, and the obtained values are the arithmetic mean of three subsequent measurements. The maximal mandibular length was measured as a distance from the midline crest of the incisor alveolus ("id" point) to a line tangent to the posterior surface of each mandibular condyle ("cdl" point). Taking into account 


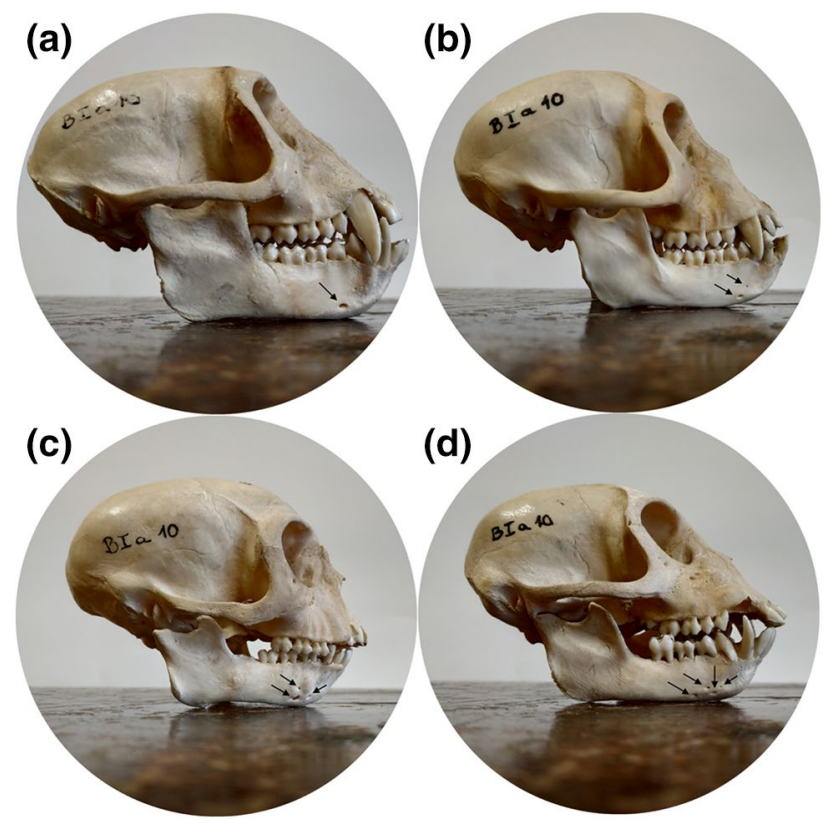

Fig. 1 Examples of dry skulls of the analyzed species with a different numbers of accessory mental foramina: (a) male skull with a single foramen; (b) male skull with two foramina; (c) male skull with three foramina; (d) male skull with four foramina. Each foramen in the individual examples is marked with a black arrow. If several foramina are present, some of them may be difficult to recognize in a lateral view because they are opening in all possible directions

the fact that the body of the mandible and ramus differ in growth rate, the distance from " $i d$ " point to a point where the ascending ramus becomes the body of the mandible (" $g o$ " point) was also measured.

Next, a skull representing one of the most common morphological types was selected and scanned using micro-computed tomography $(\mu \mathrm{CT})$. This part of the study was performed on micro-CT scanner SkyScan 1172, N.V., Aartselaar, Belgium. The scanner is equipped in an $11 \mathrm{Mpx} \mathrm{X}$-ray detector $(4024 \times 2680$ in total; $4000 \times 2400$ effective resolution), a 12 -bit CCD with a $24 \times 36 \mathrm{~mm}$ field of vision. $\mathrm{X}$-ray source voltage was set to $80 \mathrm{kV}$; image angle increment: $0.5^{\circ}$. Reconstructions of scan images were performed by means of the NRECON SkyScan software (version 1.6.5) based on the Feldkamp algorithm. Due to the limited sample size associated with the constraint imposed by the micro-CT scanning envelope, the mandible of about a 3-year-old Chlorocebus aethiops male was divided into two symmetrical halves and only the left side was scanned using micro-CT.

Statistical analysis was performed in Statistica 12.0 Software. The Shapiro-Wilk test was used as a normality test in the present study. In addition, the Mann-Whitney $U$ test was applied to compare the differences in the number of MFs between species, sex, and sides.
Table 1 Frequency of occurrence of the number of MFs in the analyzed group

\begin{tabular}{lllll}
\hline \multirow{2}{*}{ Number of MFs } & \multicolumn{3}{l}{ Chlorocebus aethiops } \\
\cline { 2 - 5 } & \multicolumn{2}{l}{ Male $[n=10]$} & \multicolumn{2}{l}{ Female $[n=9]$} \\
\cline { 2 - 4 } & $\mathrm{R}[\%]$ & $\mathrm{L}[\%]$ & $\mathrm{R}[\%]$ & $\mathrm{L}[\%]$ \\
\hline 1 & $1[10.00]$ & $1[0.00]$ & $2[22.22]$ & $1[11.11]$ \\
2 & $3[30.00]$ & $2[20.00]$ & $3[33.33]$ & $3[33.33]$ \\
3 & $3[30.00]$ & $5[50.00]$ & $3[33.33]$ & $3[33.33]$ \\
4 & $2[20.00]$ & $2[20.00]$ & $1[11.11]$ & $2[22.22]$ \\
5 & $1[10.00]$ & $0[0.00]$ & $0[0.00]$ & $0[0.00]$ \\
Total & $10[100.00]$ & $10[100.00]$ & $9[100.00]$ & $9[100.00]$ \\
\hline
\end{tabular}

\section{Results}

An estimation of the frequency of occurrence of a specific number of foramina depending on the sex and body side is summarized in Table 1. On the basis of the data, we may conclude that irrespective of sex and side, in the majority of cases 3 MFs were found, which was considered the basic type in the investigated population. In females, regardless of the side, the most common morphological type with equal percentage $(33.33 \%)$ was 2 and 3 mental foramina. However, it may be the result of a small number of skulls of this species in the sample. Despite the lack of significant differences between the investigated groups, there seems to be a tendency for greater variability in the number of MFs in males, in whom, unlike females, a case of the presence of 5 mental foramina was recorded.

Descriptive statistics values calculated separately for genders and sides indicate that most common morphological variants observed in analyzed group are three MFs. In males, it was an average of 2.9 (1.20) on the right and 2.8 (0.92) on the left side. In turn, in females, it was an average of 2.3 (1.00) on the right and 2.7 (1.00) on the left side (SD values are given in brackets). A higher variation in the MF number is seen in males, especially on the right side, which is also visible in the observed MF number range (1-5). For comparison, the range of foramina in males on the left side and females bilaterally was 1-4. Results of a Mann-Whitney $U$ test comparing the differences in the number of MFs between sides did not show statistically significant differences (0.986 in males and 0.519 in females).

In order to distinguish the main mental foramen (MF) from accessory mental foramina (AMFs), the area values of each mental foramen were estimated based on $\mu \mathrm{CT}$ images. According to the assumptions of this study, the foramen with the largest surface $1.427(0.069) \mathrm{mm}^{2}$ was considered as MF. The surface of the other foramina was, respectively: AMF1 $1.309(0.254) \mathrm{mm}^{2}$, AMF2 $0.515(0.015) \mathrm{mm}^{2}$, AMF3 0.194 $(0.026) \mathrm{mm}^{2}$ (SD values are given in brackets). 
Correlation coefficient values between mandibular length (both length of the mandible shaft ( $g o$-id) and the maximum length of the mandible ( $c d l$-id) measurements) and the ipsilateral number of MF in each case indicate a weak (positive on the right and negative on the left) and not statistically significant $(p>0.05)$ linear relationship. The results of the correlation are summarized in Table 2.

Next, the skull representing one of the more common morphological types was taken for analysis with X-ray computed microtomography. To find out if all foramina are continuous with the mandibular canal, micro-CT scans were performed to $3 \mathrm{D}$ visualize the morphology of the mandible canal and its exterior endings. Particular foramina, as well as the mandibular canal course, have been marked accordingly. The diameter of the canals has been color-coded in the software. Volumetric reconstructions of the analyzed skull in a lateral view presented in Fig. 2 indicate the presence of four mental foramina located on the mandibular body in the premolar portion. The mental foramen (MF) and accessory mental foramina (AMF 1-3) observed on the surface of the mandible constitute the exterior end of the mandibular canal (MC). Identification of each foramen was based on the assumption by Naitoh et al. (2009a, 2011) and Sisman et al. (2012) that whenever accessory mental foramina (AMF) appear, they are smaller than the main MF. It can clearly be seen that larger foramina (MF, AMF1 and AMF2) are located in close distance to each other and the smaller single foramen (AMF3) is located slightly above the "cluster". In the lateral view, the AMF3 is dimly highlighted because it is directed superiorly relative to other foramina that are making an antero posteriorly directed cluster. Moreover, AMF3 is the smallest one and the brightness level of the foramina has also been scaled to their size. For more detailed imaging of the analyzed mandible, photos were taken at various degrees of bone tissue transparency: $50 \%$ (a), 85\% (b), 97\% (c) as shown in Fig. 3. Beginning at the mandibular foramen located on the internal surface of the ramus, the mandibular canal (MC) runs obliquely down beneath an unerupted third molar and horizontally forward inside the mandible toward the symphysis in front. Canal endings are

Table 2 Correlation of mandibular length and the number of MF depending on the body side

\begin{tabular}{lllll}
\hline Variables & \multicolumn{2}{l}{ Correlations } & & \\
\cline { 2 - 5 } & $\begin{array}{l}\text { (go-id) R x } \\
\text { Number of } \\
\text { MF R }\end{array}$ & $\begin{array}{l}\text { (go-id) L x } \\
\text { MF L }\end{array}$ & $\begin{array}{l}(c d l-i d) \text { R x } \\
\text { Number of } \\
\text { MF R }\end{array}$ & $\begin{array}{l}(c d l \text {-id) L x } \\
\text { Number of } \\
\text { MF L }\end{array}$ \\
\hline $\begin{array}{l}\text { Correlation } \\
\text { coefficient } \\
(r)\end{array}$ & 0.2158 & -0.1774 & 0.1981 & -0.1240 \\
$p$
\end{tabular}

(go-id) the length of the mandible shaft, (cdl-id) the maximum length of the mandible

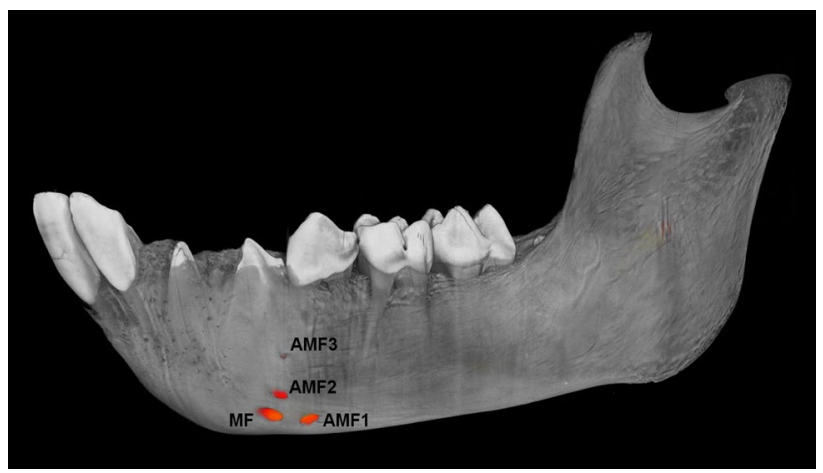

Fig. 2 A lateral view of the left side of the analyzed mandibular bone. Marked is the presence of the main mental foramen (MF) as well as accessory foramina (AMF1, AMF2, AMF3)

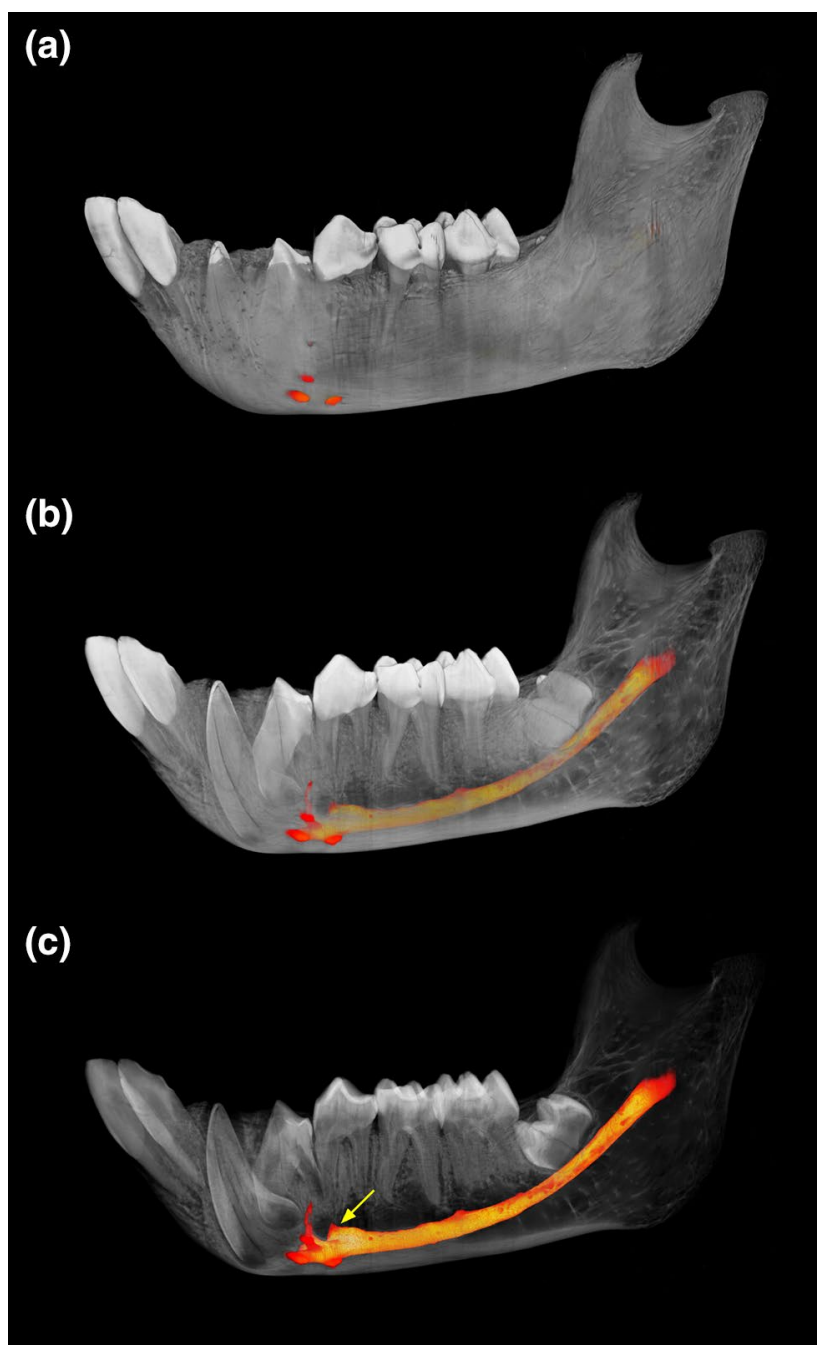

Fig. 3 A 3D visualization with marked mandibular canal course and mental foramina at various degrees of bone tissue transparency: $50 \%$ (a), $85 \%$ (b), 97\% (c). A yellow arrow shows bifurcation of the incisive canal and mandibular canal localized inferior to the premolar roots 
located in the premolar region, forming four mental foramina (MF, AMF1, AMF2 and AMF3). Each of the mental foramina observed on the anteroexternal surface of the mandible is the exterior end of the bifurcating mandibular canal. Figure $3 \mathrm{~b}, \mathrm{c}$ shows the presence of four small neurovascular bundle bony canals formed during an individual's lifetime by terminating branches of the inferior alveolar bundle.

A lateral view of the analyzed mandible presented in Fig. 4 illustrates the course of the mandibular canal (MC) at a variable distance from the outer surface of the mandibular shaft. In the analyzed case, the pathway of the MC is not consistent. The course of the MC begins on the inside of the mandibular ramus and bends twice in its entire length. MC is being closest to the outer edge of the mandibular shaft for the first time near the second molar and for the second time nearby the mental foramina. Over its entire length, the MC has a variable crosssectional area (cf. Fig. 5). Prominently, the smallest MC width is in the area of the unerupted third molar. The MC is the widest in the premolar region, which is associated with the canal bifurcation of the incisive nerve.

Subsequently, morphometric analysis of $\mu \mathrm{CT}$ of the mandibular canal (MC) and its external openings: the mental foramen (MF) and accessory mental foramina (AMF1, AMF2, AMF3), were made. The results are shown in Fig. 5. It is noteworthy that particular mental foramina do not form typical bony canals. Rather, they constitute several small external openings with common space inside the body of the mandible. The exception is AMF3, the location of which away from the main cluster resulted in the presence of a narrow canal leading to it. The diameter of the canals has been color-coded in the software.

According to literature data (Olivier 1928; Carter and Keen 1971; Chávez-Lomeli et al. 1996; Naitoh et al. 2009b; Liu et al. 2009), morphology and course of the MC may have implications for the number of mental foramina. In connection with above, the morphology of the MC was visualized which is presented in Fig. 6. In the analyzed case, however, no multiplicity of the MC was observed. The inferior alveolar neurovascular bundle during an individual's lifetime was found to run in a clearly defined canal which is located inside the mandible. The bony canal at its superior surface contains several openings arranged at regular distances (blue arrows), through which the neurovascular bundles passed to supply particular teeth. A similar canal, denoted as canalis sinuosis, was described for the anterior superior alveolar bundle in the maxillary bone (Shelley et al. 1999; Oliveira-Santos et al. 2013).

\section{Discussion}

The human skull is characterized by the presence of a single mandibular canal terminating with a single mental foramen on the buccal surface of the mandible. However, occasional variations in the morphology of these two bony structures have been observed. The process of formation of multiple canals and, thus, multiple mental foramina of the human mandible was described in Chávez-Lomeli et al.'s (1996) report. However, this report does not explain the simultaneous presence of a single mandibular canal terminating with multiple mental foramina as it happens in the material we analyze. Naitoh et al. (2009b) suggested that separation of the mental nerve into several fasciculi earlier than the formation of the mental foramen until the 12th gestational week could be a reason for the formation of an accessory mental foramen.

Lande (1952) showed that the growth of the alveolar process does not keep up with the growth of the base of the mandible in the horizontal direction. The differential combination of alveolar regression and progressive mandibular growth is responsible for the unique human mental prominence - an autapomorphic trait of the Homo sapiens (Enlow 1968). Consequently, in cases where the distance from the MF to the anterior border of the mandible is increased, that is, when the chin is strongly protruding, each of the mental branches after the anterior loop is more widely separated and many branching foramina from the nerve bundles can be formed. This, however, does not explain the multiplicity of the MF in non-human primates (NHP) that have no mental prominence because the alveolar bone of NHPs grows forward and faster in the long run than the basal bone (the shaft and the branch of the mandible), underlying that which explains the prognathism observed in jaws of the NHPs (Schwartz and Huelke 1963).

A completely opposite explanation, referring to the records of the fossil man, was made by Warwick (1950), who found that two or more mental foramina were present in those forms in which the mental eminence was either missing or ill-developed but represented by a single foramen in those forms which featured a prominent chin, which, in the absence of the mental prominence in NHPs, could explain the multiplicity of the MF.

According to Mota et al. (2010), the mandibular body grows more rapidly than the ramus, both in length and height, while symphysis height displays the highest growth rate. Two completely opposite conclusions reached Berraquero et al. (1995). This ambiguity caused that in this research, we decided to correlate both the maximum length of the mandible ( $i d-c d l$ ) and the length of the mandible shaft (id-go) with the ipsilateral number of MF (Table 2). Nevertheless, in the material we analyzed, the correlations were very weak and not statistically significant.

In most studies, no relationship was found between the presence of an additional mandibular canal (MC) and sex or age (e.g., Kang et al. 2014; Fuentes et al. 2019) as well as no significant sex-related, side-related and age-related differences in the AMF (Mouri 1990; Toh et al. 1992; Lam 

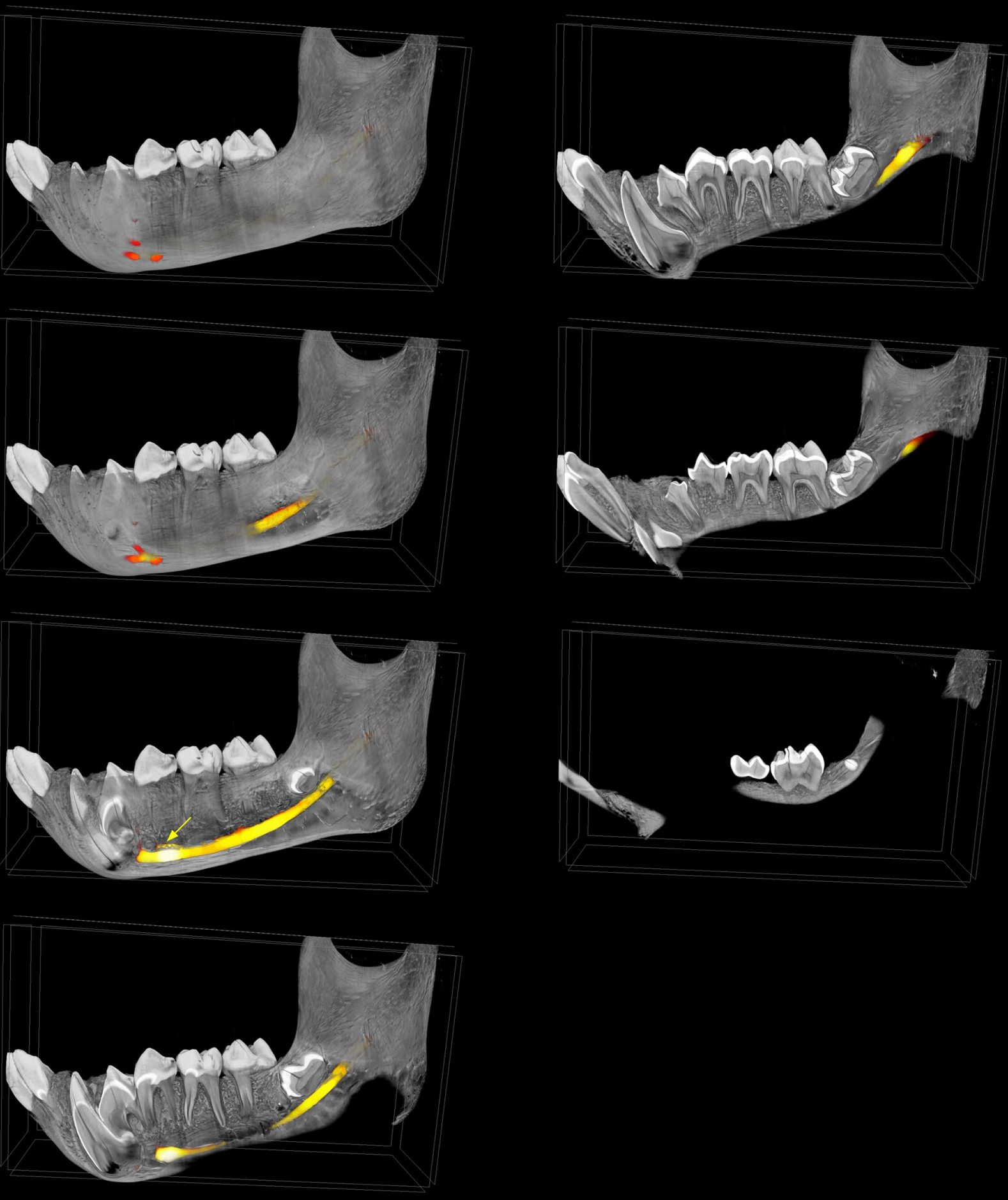

Fig. 4 A 3D visualization with marked mandibular canal course and mental foramina using virtual sagittal plane cross section. A yellow arrow shows bifurcation of the incisive canal and mandibular canal localized inferior to the premolar roots

et al. 2019). However, some reports suggest such relationships (Sawyer et al. 1998; Hanihara and Ishida 2001). In the material we analyzed, no significant differences in terms of sex and side were recorded.
The first example of the mental foramen's (MF) multiplicity in primates was described by Patruban (1865). The human bone material he analyzed contained a mandible characterized by the presence of two MFs on each side. Gruber 


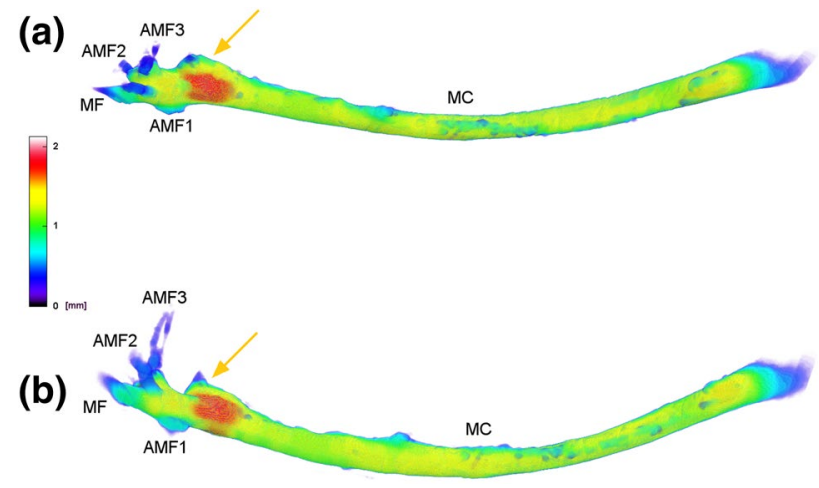

Fig. 5 Morphometric analysis of $\mu \mathrm{CT}$ mandibular canal (MC) and its openings: mental foramen (MF) and accessory mental foramina (AMF1, AMF2, AMF3). The diameter of the channels has been color-coded in the software. (a) Superior view of the mandibular canal; (b) lateral view of the mandibular canal. Yellow arrows show bifurcation into the short incisive canal

(1874) and Bertelli (1900) noted for the first time a very rare tripartite MF. However, many years earlier Serres (1819) and Cruveilhier (1829) as well as Rambaud and Renault (1864) in an anatomical atlas about the origin and development of bones, illustrated human mandibles with accessory mental foramina. Le Double (1903), in his summary of the comparative anatomy of multiple mental foramina, argued that the condition is normal in the whale, dolphin, pig, camel, dog, cat, bat, and in many monkeys, except that higher monkeys and apes tend to show a reduction to a single mental foramen. According to Simonton (1923), 39\% of orangutans, $27 \%$ of gorillas and $15 \%$ of chimpanzees had AMFs. Gregory (1920) showed that among Adapidae-a family of fossil primates-on average, 3 MFs were observed and among Notharctidae-4 MFs. Harris (1927) observed that due to the average frequency of occurrence of accessory mental foramina in the primate skull series he studied, they can be arranged in a gradient: chimpanzees (average 1.00 on both sides), gibbons (average 1.00 on both sides), gorillas (1.11 on the right, 1.04 on the left), narrow-nosed monkeys (1.36 on the right, 1.48 on the left), orangutans (1.39 on the right, 1.50 on the left), lemurs ( 3.00 on the right, 2.00 on the left). Subsequent studies confirmed some previous reports that the Pan and Papio species relatively often have accessory mental foramina (Swindler and Wood 1982). The anatomy of the mandible in primates, including humans (Iwanaga et al. 2016), Hamadryas baboons (Fukase 2011), Macaca mulatta (Turpin 1968) and New World monkeys (Takai et al. 2000) has also been the subject of a few subsequent studies. As Mouri (1990) noticed the pattern of foramina or canals multiplicity constituting the cranial nerves exit in macaques is extremely variable. In the study conducted by Iwanaga et al. (2017), 9/10 hemimandibles had an accessory mental opening, which may suggest that Macaca fascicularis
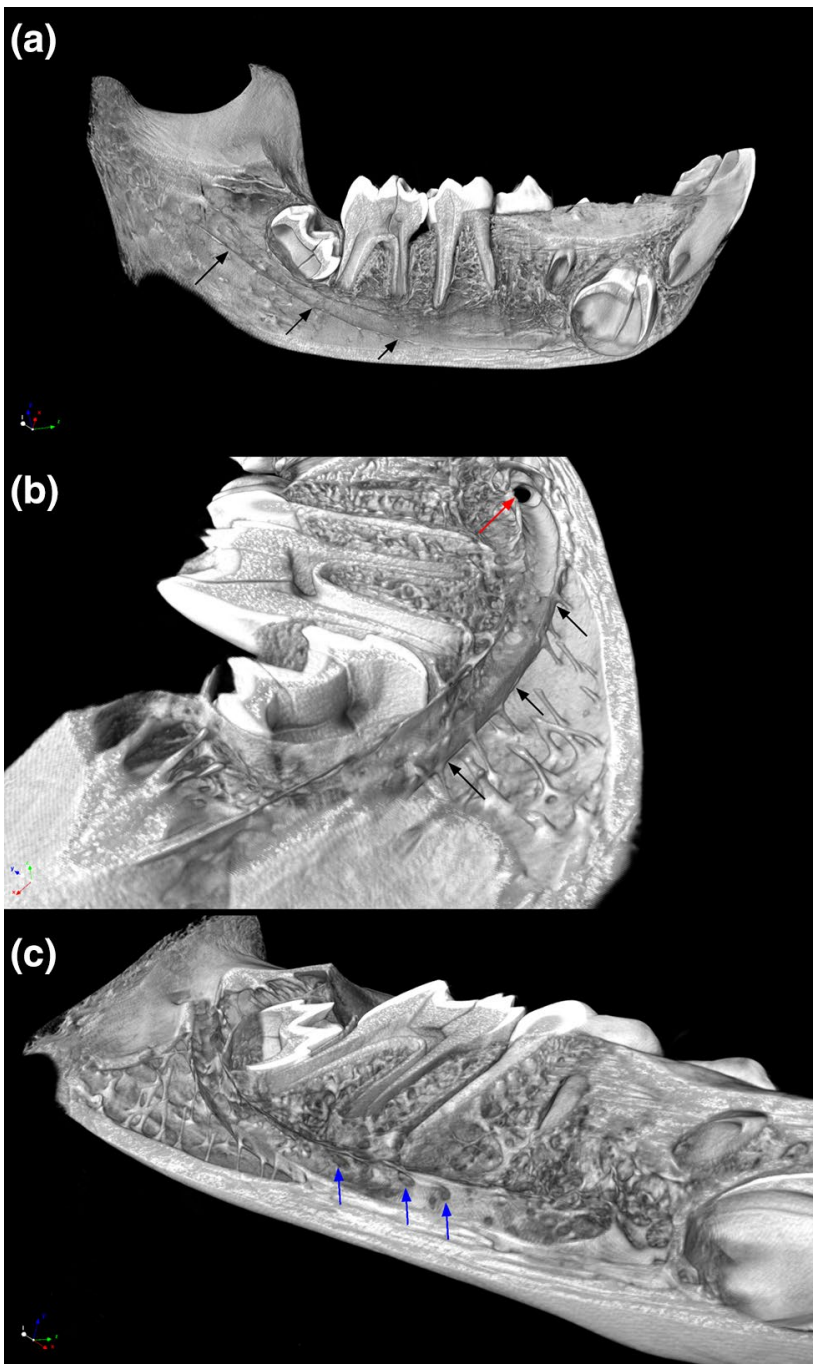

Fig. 6 A 3D visualization using a virtual sagittal plane cross section of the left hemimandible containing a distinct mandibular canal course: (a) lateral view of the mandibular canal course with the osseous margins of the canal (black arrows), (b) posterolateral view of mandibular canal course (black arrows) and the lumen of the canal (red arrow) in the place of its curvature, (c) anterolateral view of mandibular canal course with small and spaced at regular distances openings on its superior surface (blue arrows). These foramina are a passage for the nerve branches to the particular molars and premolars during the lifetime of the individual

is most often characterized by the presence of an accessory mental foramen. Sunohara et al. (2017) in the morphological study of the Japanese macaque (Macaca fuscata) skulls using cone beam computed tomography (CBCT) analyzed the occurrence of mandibular canal multiplicity. All of the analyzed skulls were characterized by a single mandibular canal, but the authors observed multiple mental and lingual foramina, too. Although the purpose of Kim et al.'s (2019) study was to investigate the relationship between masticatory muscular hypotrophy and mandibular growth in juvenile nonhuman primates (Macaca fascicularis), 3D computed 
tomography of the analyzed cynolmolgus monkey's hemimandible shows three MFs.

Moreover, many reports were published about the location of the MF in the primate's mandible. Reported locations of the MF and the AMF differ by source. Bünte and Moral (1910), and Schulz (1933) stated that in the majority of the cases examined by them the single mental foramen (MF) in humans opened backwards and upwards; while in the anthropoids, the foramen was directed forwards. Warwick (1950) found that in fetuses, the mental nerve is non-tortuous in its course; whereas in adults, it is always tortuous. Furthermore, while in newborns the direction of the nerve corresponds to the direction of the foramen, that is, anteriorly and superiorly, in adults the nerve trunk and hence a mental foramen are directed posteriorly. Weidenreich (1936) points out that in Sinanthropus, the mental foramina vary between 2 and 5 in number and open in all directions. According to more recent studies, the human AMF is often located "posteroinferior" to the MF (Naitoh et al. 2009a; Sisman et al. 2012; Orhan et al. 2013; Neves et al. 2014). Others report its location as "posterior" (Katakami et al. 2008; Göregen 2013), "anteroinferior" (Kalender et al. 2012) or just near the MF. It seems, however, that accessory mental foramina (AMFs) are located in the rear of the MF more often than in front of it. From similar studies on NHPs, it can be concluded that the location of the mental foramen in the gorilla is more anteriorly, while in the chimpanzee is more posteriorly. In the investigated taxa, apart from the chimpanzee, the anterior-posterior position of the mental foramen is positively allometric in relation to the length of the alveolar arch. The longer the alveolar arch, the further the mental foramen is positioned to the rear. In all the skulls of Chlorocebus aethiops we analyzed, on average 2-3 MFs (range 1-5), opening in all directions, were most often observed on each side. In the $\mu \mathrm{CT}$ analysis we made, the MF is directed anteriorly, AMF1 posteriorly, AMF2 anterosuperiorly and AMF3 markedly superiorly (Fig. 2). A significant difference between hominins and monkeys is the overall size of canines as well as canine sexual dimorphism. Enlarged canine roots, like in Chlorocebus aethiops, can affect the place where the lower alveolar nerve and blood vessels exit the mandibular body. Such canine morphology may limit the anterior extension of the mandibular canal resulting in the relatively more posterior location of anterior foramina. All of these morphological features of the mandible may provide useful information for surgical treatment of the alveolus in a human model (e.g., when administering local anesthesia).

Although AMF definitions have been proposed by many researchers, it is very difficult to establish the borderline between small the AMF and the usual nutrient foramen, as some AMFs have vague continuity with the mandibular canal. Perhaps, this could be why the AMF's frequency of occurrence is very different across many individual reports. $\mu \mathrm{CT}$ produces reliable high-resolution images that allow better visualization of analyzed structures. In addition, 3D reconstructions are helpful in the identification of AMFs and differentiating them from nutrient foramina. The use of $3 \mathrm{D}$ visualization in this case (Figs. 2, 3, 4, 5, 6) confirms and illustrates the presence of three AMFs. The AMF is defined as a bony foramen that originated from the mandibular canal, as observed in this case. Nutrient foramina, on the other hand, do not originate from the mandibular canal and their dimensions are significantly smaller (Serman 1987). In the material we analyzed, 3 AMFs are clearly connected to the mandibular canal (MC) (Figs. 3, 5).

The mandibular canal extends from the mandibular foramen at the inner aspect of the ramus to the mental foramen along the mediolateral aspect of the mandible, thus traversing the mandibular body (von Arx and Lozanoff 2017). Typically, the canal goes obliquely down through the spongy bone of the mandibular branch and reaches the shaft, lying at equal distances between the lingual and buccal surface of the compacted bone (Majewski and Majewski 2008). Actually, distances from the mandibular canal to adjacent bone surfaces of the mandibular body largely depend on the course of the mandibular canal within the mandible, which, in turn, is affected by multiple factors such as shape or bony surface atrophy and, thus, on the site of measurement. According to von Arx and Lozanoff (2017), the reported mean distances from the mandibular canal to the buccal surface of the mandible and to the lingual surface of the mandible, are, respectively: $3.8-8.5 \mathrm{~mm}$ and $2.1-5.8 \mathrm{~mm}$. According to Juodzbalys et al. (2010), the mandibular canal stretches throughout the mandibular body forming an S-like shaped pattern and it does not run centrally but is located closer to the lingual side of the jaw. Between the first and second premolars, the canal turns sharply towards the buccal surface and opens outwards as the mental foramen (cf. Fig. 3). A 3D visualization of the material we analyzed suggests that the course and morphology of the mandibular canal are very similar to that of a human, except that, as shown in Fig. 4, the canal does not lie at an equal distance between the buccal and lingual surfaces and it terminates with several mental foramina, each of which is an external opening of a very short and narrow canal. In the case of the analyzed skull, the smallest foramen (AMF3) is located a little further and higher in relation to other openings. However, a narrow and small yet distinct bony canal leads to it (Fig. 3b, c). Liu et al. (2009) described high variability in the course and shape of the MC and classified the MC course into four distinct patterns. The Chlorocebus aethiops's skull we analyzed has a simple, slightly linear/curved (approximate to a straight line) mandibular canal classified by Liu et al. (2009) as most commonly found in humans.

In human anatomy, the mandibular canal continues forward toward the symphysis where it splits into two smaller 
canals that reach up toward the incisors (Soams 1995). According to Mortazavi et al. (2019), in the region of the first molar to the second premolar, the inferior alveolar nerve branches into the incisive and mental nerves. In the present study, we were unable to recognize the incisive canal. This could have been due to the presence of an unerupted canine, which blocked the straight pathway for the incisive canal (Figs. 3, 4). However, when observed by means of a binocular magnifier, the sagittal cross section of the mandibular symphysis in the Chlorocebus aethiops revealed a small canal located at the bottom of the mandibular body in the incisor region. It seems that the presence of an unerupted canine possibly forced the inferior alveolar nerve (IAN) to give off the incisive nerve and find its pathway to the odontogenic root zone of the incisors slightly more medially than in the human mandible. This bifurcation, which may act as an incisive canal, is visible in Figs. 3c, 4 and 5a, b (yellow arrows). Unfortunately, this bifurcation ends at some point; so, it was impossible to clearly determine its further course.

Within the mandibular canal, the inferior alveolar nerve runs in the hard periosteal sheath extending from the mandibular foramen to the mental foramen (as shown in Fig. 6). The inferior alveolar nerve runs inside the mandibular canal formed by hard periosteal sheath extending from the mandibular foramen to the mental foramen (as shown in Fig. 6). While in the mandibular canal, it supplies lower teeth by giving off vertical sensory branches that penetrate the superior surface of the bony sheath (Fig. 6c; blue arrows). This periosteal coating also covers the inferior alveolar artery and vein and the central lymphatic vessel of the mandible (hence, it cannot be called a perineural sheath) (Majewski and Majewski 2008; von Arx and Lozanoff 2017). Distal to the mental foramen, the inferior alveolar nerve gives off branches to the canine and incisors and runs medially in its own canal within the spongy bone already without the periosteal sheath as the anterior inferior alveolar nerve. Olivier (1928) and later Carter and Keen (1971) found 40\% of dissected mandibles lack a distinct bony canal sheath. Instead, the inferior alveolar neurovascular bundle ran through the trabecular bone of the mandibular corpus. Also, Manikandhan et al. (2010) described a case of the extracanal course of the lower alveolar nerve. After extreme vertical resorption of the mandibular bone, the lower alveolar nerve may lie in the superficial groove of the mandible without the bony roof, and therefore only covered with soft tissue (Rusu et al. 2011). In the case study of a bifid inferior alveolar neurovascular bundle in the human mandible reported by Ramirez (2019), an inferior branch of neurovascular bundle ran within a distinct bony canal, while the superior one passed through the trabecular bone of the mandibular corpus.

Carter and Keen (1971) described distinctive courses of the mandibular canal (MC) relative to the pattern of distribution of the inferior alveolar nerve (IAN) and formulated three morphological types based on this. Given the morphology and vicinity of the mandibular canal to the root apices of the molars in the analyzed material (because of its non-eruption, the third molar was located closest to the mandibular canal, about 20-50 microns at the point of contact), we may suppose that the IAN was a single large structure lying in a bony canal and the branches supplying the molar roots were very short and direct; therefore, the analyzed canal course most likely represents Type I. Our case also represents Type I described by Olivier (1928), which is observed in $66 \%$ of human cases and which displayed a single bundle that traveled within the bony canal and divided into two terminal branches near the mental foramen region: the mental nerve and the incisive nerve, respectively, as well as the Type I described by Liu et al. (2009), which is a linear curve (an approximately straight line).

Studies regarding the multiplicity of the mental foramen, mandibular canal course and associated neurovascular bundles in non-human primates are extremely limited in number. Some of them reported that the mandibular nerve distribution in the Macaque was seen to be very similar to that found in man (Schwartz and Huelke 1963; Iwanaga et al. 2017). Schwartz and Huelke (1963) described mastication muscles and the course of the mandibular branch of the trigeminal nerve (CNV3), by which these muscles are innervated, in macaque rhesus, and stated that they are generally similar to those in humans with very slight and non-significant differences. Authors claimed that mandibular nerve (CNV3) in macaque rhesus originated from the trigeminal ganglion in the middle cranial fossa just like in humans and passed downward a short distance to the foramen ovale. When the mandibular nerve passed through the foramen ovale, it is divided into a smaller anterior division and a larger posterior division (Schwartz and Huelke, 1963). Whereas, Iwanaga et al. (2017) observed the presence of mandibular angular branches in Macaca fascicularis which have never been reported in a corpse or human clinical study. The authors assumed that the long mandibular body required branching of the angular branches of the Macaca fascicularis mental nerve covers a wide range of skin surface sensation. In addition, mental branches were much shorter than other branches. This can be attributed to the proximity of the mental foramen and the mandibular symphysis in the macaque.

Many studies (Kamijo 1967; Clemente 1984; Alsaad et al. 2003; Göregen 2013) described mental nerve (MN) distribution. Kamijo (1967) describes that the MN usually divides into two branches: the lower labial and mental. The lower labial branch is running toward the angular regions, sometimes dividing into angular branches. Hu et al. (2007) described four branches of the MN: angular, medial inferior labial, lateral inferior labial, and mental. These nerve branches were classified into five types based on their 
branching patterns. Won et al. (2014) visualized MN branch distribution patterns using Sihler's staining technique and described four branches. By means of dissection under a surgical microscope and using 3D reconstruction, Alsaad et al. (2003) described MN cutaneous branches and observed three distribution patterns which were identified as vertical, horizontal and oblique. According to Toh et al. (1992), the AMN innervation patterns may vary depending on how MF and AMF locations are related because AMN fibers complement some areas where the $\mathrm{MN}$ is not distributed.

According to Naitoh et al. (2009a, 2011) and Sisman et al. (2012), if accessory foramina appear, they are smaller than the MF. The average MF area in the analyzed material corresponds to the average AMF area in the human mandible (Naitoh et al. 2009a). The authors also emphasize that the larger the AMF area, the smaller the ipsilateral MF area. This hypothesis is confirmed by histological results for the AMN, which were similar and non-specific to a normal MN bundle (von Arx et al. 2014). The MF area in some way allows assessing the mechanoreceptive abilities of the mandible (Muchlinski and Deane 2016). Trigeminal innervation provides both sensory and motor information to most soft and hard tissues of the masticatory apparatus and face. The mental nerve also innervates the mandibular vibrissae (Gao et al. 2001; The et al. 2013). In the few studies on the role of submandibular vibrissae, we know that these whiskers are stationary and very variable among mammals (Pocock 1914; The et al. 2013). Both Prosimians and most Haplorrhini have mandibular micro-vibrissae and the submandibular vibrissae (Pocock 1914; Muchlinski 2010). For the animal, the submandibular vibrissae allow constant self-control in environmental space and help in assessing speed. Muchlinski and Deane (2016) stated that, in contrast to the infraorbital foramen (IOF), the mental foramen, and thus the mental nerve, does not correlate well with dietary categories and although the lower lip is also involved in manipulating food and helping to make food intake decisions, more emphasis appears to be placed on the upper lip for this function. However, considering the similarity to mystical vibrissae innervated by the IOF, submandibular vibrissae can play an important dietary function. Nevertheless, the lack of dietary correlation may be due to the fact that the authors used qualitative categories to assign diet, which is often inconclusive for some species as well as the use of MF surfaces, which usually does not transfer nerves that supply individual teeth. As shown in Fig. 5, cross-sectional area of the incisive nerve canal that bifurcate from the main branch is quite sizable. It is the incisors in many primates that help evaluate food and its pretreatment. Therefore, it seems that the canal cross-sectional area or the mandibular foramen area would be more suitable to assess dietary correlations. Future research should include additional measurements of mandibular features to further examine the evolutionary implications of the variation in the mandibular canal and mental foramina.

Ontogenetical studies conducted only on modern humans revealed a possible mechanism of accessory mental foramina forming dento-mandibular development (Toh et al. 1992; Katakami et al. 2008; Naitoh et al. 2009b; Iwanaga et al. 2015). Therefore, additional comparisons with non-human primates should further elucidate the mechanisms underlying the inter-species variation.

The limitations of this study that could have the greatest potential impact on the quality of our findings might be the fact that the study was conducted only on representatives of the Chlorocebus aethiops species (homogeneous population) and that the frequency of occurrence of the AMF was assessed with small sample size. Thus, this subset is not large enough to accurately assess prevalence. Basing our study on larger sample size and other primate species might have generated more accurate results and built a stronger overall evidence base. Moreover, a relatively small amount of research on non-human primates in this field limits the scope and depth of discussion in this paper.

Author contributions $\mathrm{KM}$ was responsible for all data collection, analyses, and writing of the manuscript. JM and HG supervised the research and helped with writing the manuscript. BL and AW performed micro-CT measurements. All authors read and approved the final manuscript.

Funding The authors received no financial support for the research, authorship, and/or publication of this article.

\section{Compliance with ethical standards}

Conflict of interest There are no conflicts of interest for any of the authors.

Ethical approval No animals were involved, skulls were from existing collections. No humans were involved.

Human and animal rights statement This article does not contain any studies with human participants or animals, performed by any of the authors.

Open Access This article is licensed under a Creative Commons Attribution 4.0 International License, which permits use, sharing, adaptation, distribution and reproduction in any medium or format, as long as you give appropriate credit to the original author(s) and the source, provide a link to the Creative Commons licence, and indicate if changes were made. The images or other third party material in this article are included in the article's Creative Commons licence, unless indicated otherwise in a credit line to the material. If material is not included in the article's Creative Commons licence and your intended use is not permitted by statutory regulation or exceeds the permitted use, you will need to obtain permission directly from the copyright holder. To view a copy of this licence, visit http://creativecommons.org/licenses/by/4.0/. 


\section{References}

Ahmed S, Jasani V, Ali A et al (2014) Double accessory mental foramina: report of an anatomical variant. Oral Surg 8:51-53

Aitchison J (1965) Contrasts in the mandibles and mandibular teeth of the chimpanzee, orangutan and gorilla. Dent Mag Oral Top $81: 105-108$

Alsaad K, Lee TC, McCartan B (2003) An anatomical study of the cutaneous branches of the mental nerve. Int J Oral Maxillofac Surg 32(3):325-333

Ari I Kafa IM, Basar Z, Kurt MA (2005) The localization and anthropometry of mental foramen on late Byzantine mandibles. Coll Antropol 29:233-236

Ashton EH, Oxnard CE (1958) Some variations in the maxillary nerve of Primates. J Zool 131:457-470

Berraquero R, Palacios J, Gamallo C et al (1995) Prenatal growth of the human mandibular condylar cartilage. Am J Orthod Dentofac Orthop 108(2):194-200

Bertelli D (1900) Short Note at the Congress of the Anatomische Gesellschaft, Pavia

Bünte H, Moral H (1910). Úber das foramen mentale. Korrespondenzblatt für Zahnārzte. Berlin, XXXIX, 140-153, fig., 2 pls

Cagirankaya LB, Kansu H (2008) An accessory mental foramen: a case report. J Contemp Dent Pract 9:98-104

Carter RB, Keen EN (1971) The intramandibular course of the inferior alveolar nerve. J Anat 108:433-440

Chávez-Lomeli ME, Lory JM, Pompa JA et al (1996) The human mandibular canal arises from three separate canals innervating different tooth groups. J Dent Res 75:1540-1544

Clemente CD (1984) Gray's Anatomy thirtieth, American edn. Lea and Febiger, Philadelphia, pp 1168-1169

Cruveilhier M (1829) Apoplezie. Dict de Med et Chirurg

Enlow DH (1968) The human face. Harper and Row, New York

Fuentes R, Arias A, Farfan C et al (2019) Morphological variation of the mandibular canal in digital panoramic radiographs: a retrospective study in a Chilean population. Folia Morphol 78(1):163-170

Fukase H (2011) Relationship between canine dimorphism and mandibular morphology in the hamadryas baboon and the Japanese monkey. Am J Phys Anthropol 144(4):607-616

Fukase H (2014) Spatial relationship between the mental foramen and mandibular developing teeth in modern humans, chimpanzees, and hamadryas baboons. Am J Phys Anthropol 154(4):594-603

Gao P, Bermejo R, Zeigler HP (2001) Whisker deafferentation and rodent whisking patterns: behavioral evidence for a central pattern generator. J Neurosci 21:5374-5380

Gershenson A, Nathan H, Luchansky E (1986) Mental foramen and mental nerve: changes with age. Cells Tissues Organ 126(1):21-28

Göregen M (2013) The assessment of accessory mental foramina using cone beam computed tomography. Turk J Med Sci 43:479-483

Gupta S, Soni JS (2012) Study of anatomical variations and incidence of mental foramen and accessory mental foramen in dry human mandibles. Natl J Med Res 2(1):28-30

Green RM (1987) The position of the mental foramen: a comparison between the Southern (Hong Kong) Chinese and other ethnic and racial groups. Oral Surg Oral Med Oral Pathol 63:287-290

Gregory WK (1920) On the structure and relations of Notharctus, an American Eocene primate. Memoirs of the AMNH; new ser., vol 3, pt 2

Gruber W (1874) Ueber die infraorbitalkanale dem Menschen und bei den Saugetheiren. St, Petersburg

Grzybowski J (1927) Etude sur les echancrures et les trous suborbitaires et sur les trous sousorbitaires chez les Primates. (Study of the openings and the suborital holes and of the sub-suborbital holes in primates.) C. R. Soc. Sci, Varsovie, Cl. 3, 20, 481-503

Hanihara T, Ishida H (2001) Frequency variations of discrete cranial traits in major human populations. IV. Vessels and nerve related variations. J Anat 199(3):273-287

Harris HA (1927) The skull, the face, and the teeth of primates, with special reference to Dolichocephaly and the Centres of growth in the face-part I. Proc Zool Soc Lond 97(3):491-502

Hu KS, Yun HS, Hur MS et al (2007) Branching patterns and intraosseous course of the mental nerve. J Oral Maxillofac Surg 65:2228-2294

Igarashi C, Kobayashi K, Yamamoto A et al (2004) Double mental foramina of the mandible on computed tomography images: a case report. Oral Radiol 20:68-71

Iwanaga J, Saga T, Tabira Y et al (2015) The clinical anatomy of accessory mental nerves and foramina. Clin Anat 28(7):848-856

Iwanaga J, Watanabe K, Saga T et al (2016) Accessory mental foramina and nerves: application to periodontal, periapical, and implant surgery. Clin Anat 29(4):493-501

Iwanaga J, Watanabe K, Saga T et al (2017) Radiological and microsurgical anatomy for variation of the mandible: comparative study of human and Macaca fascicularis. Anat Record 300(8):1464-1471

Jha AK, Kumar NG (2012) Accessory mental nerve: case report, review and its role in trigeminal neuralgia. Surg Radiol Anat $34: 469-473$

Juodzbalys G, Wang HL, Sabalys G (2010) Anatomy of mandibular vital structures. Part II: mandibular canal and inferior alveolar neurovascular bundle in relation with dental implantology. J Oral Maxillofac Res 1:e3

Kadanoff D, Mutafov ST, Jordanov J (1970) Über die Hauptöffnungen resp. Incisurae des Gesichtsschädels (Incisura frontalis seu Foramen frontale, Foramen supraorbitale seu Incisura supraorbitalis, Foramen infraorbitale, Foramen mentale). Gegenbaurs Morphol Jahrbuch 115:102-118

Kalender A, Orhan K, Aksoy U (2012) Evaluation of the mental foramen and accessory mental foramen in Turkish patients using cone-beam computed tomography images reconstructed from a volumetric rendering program. Clin Anat 25:584-592

Kamijo Y (1967) Oral anatomy, 1st edn. Anatom Co., Tokyo

Kang JH, Lee KS, Oh MG et al (2014) The incidence and configuration of the bifid mandibular canal in Koreans by using conebeam computed tomography. Imaging Sci Dent 44:53-60

Katakami K, Mishima A, Shiozaki K et al (2008) Characteristics of accessory mental foramina observed on limited cone-beam computed tomography images. J Endod 34:1441-1445

Kim HJ, Tak HJ, Moon JW et al (2019) Mandibular vertival growth deficiency after botulinum-induced hypotrophy of masticatory closing muscles in juvenile nonhuman primates. Front Physiol 10:496

Lam M, Koong C, Kruger E, Tennant M (2019) Prevalence of accessory mental foramina: a study of 4,000 CBCT scans. Clin Anat 32:1048-1052

Lande MJ (1952) Growth behavior of human bony facial profiles as revealed by serial cephalometric roentgenology. Angle Orthod 22:78-90

Le Double AF (1903) Traité des variations des os du crane de l'homme, et de leur signification au point de vue de l'anthropologie zoologique. Vigot Frères, Paris

Lindh C, Petersson A, Kling B (1995) Measurements of distances related to the mandibular canal in radiographs. Clin Oral Implant Res 6:96-103

Liu T, Xia B, Gu Z (2009) Inferior alveolar canal course: a radiographic study. Clin Oral Implan Res 20(11):1212-1218

Majewski S, Majewski P (2008) Uwarunkowania anatomiczne implantacji śródkostnej w szczęce i żuchwie (Anatomical 
conditions in intraoseeous implantation in maxilla and mandibula). Implantoprotetyka, T.9, $\mathrm{nr} 4$, s. 10-20

Manikandhan R, Mathew PC, Naveenkumar J et al (2010) A rare variation in the course of the inferior alveolar nerve. Int J Oral Maxillofac Surg 39(2):185-187

Montagu MFA (1954) The direction and position of the mental foramen in the great apes and man. Am J Phys Anthropol 12:503-518

Mortazavi H, Baharvand M, Safi Y et al (2019) Common conditions associated with mandibular canal widening: a literature review. Imaging Sci Dent 49(2):87-95

Mota RS, Cardoso VAC, CdeS B et al (2010) Análise do crescimento das dimensões da mandíbula em diferentes idades fetais. Dental Press J Orthod 15(2):113-121

Mouri T (1990) A comparison of eight macaque species according to four kinds of cranial nerve perforations. J Anthropol Soc Nippon 98(4):411-423

Msuya CP, Harrison T (1994) The circumorbital foramina in primates. Primates 35(2):231-240

Muchlinski MN (2010) A comparative analysis of vibrissa count and infraorbital foramen area in primates and other mammals. J Hum Evol 58:447-473

Muchlinski MN, Deane AS (2016) Dietary correlates associated with the mental foramen in primates: implications for interpreting the fossil record. J Morphol 277(7):978-985

Mraiwa N, Jacobs R, van Steenberghe D et al (2003) Clinical assessment and surgical implications of anatomic challenges in the anterior mandible. Clin Implant Dent Relat Res 5:219-225

Naitoh M, Hiraiwa Y, Aimiya H et al (2009a) Accessory mental foramen assessment using cone-beam computed tomography. Oral Surg Oral Med Oral Pathol Oral Radiol Endod 107:289-294

Naitoh M, Hiraiwa Y, Aimiya $\mathrm{H}$ et al (2009b) Observation of bifid mandibular canal using cone-beam computerized tomography. Int J Oral Maxillofac Implants 24:155-159

Naitoh M, Yoshida K, Nakahara K et al (2011) Demonstration of the accessory mental foramen using rotational panoramic radiography compared with cone-beam computed tomography. Clin Oral Implants Res 22:1415-1419

Neves FS, Nascimiento MCC, Oliveira ML et al (2014) Comparative analysis of mandibular anatomical variations between panoramic radiography and cone beam computed tomography. Oral Maxillofac Surg 18:419-424

Oliveira-Santos C, Souza PH, De Azambuja B-C et al (2011) Characterisation of additional mental foramina through cone beam computed tomography. J Oral Rehabil 38:595-600

Oliveira-Santos C, Rubira-Bullen IR, Monteuri SA et al (2013) Neurovascular anatomical variations in the anterior palate observed on CBCT images. Clin Oral Implants Res 24:1044-1048

Olivier E (1928) The inferior dental canal and its nerve in the adult. Br Dent J 49:356-358

Orhan AI, Orhan K, Aksoy S et al (2013) Evaluation of perimandibular neurovascularization with accessory mental foramina using cone-beam computed tomography in children. J Craniofac Surg 24:365-369

Pancer B, Garaicoa-Pazmino C, Bashutski JD (2014) Accessory mandibular foramen during dental implant placement: case report and review of literature. Implant Dent 23:116-124

Patil S, Matsuda Y, Nakajima K et al (2013) Retromolar canals as observed on cone-beam computed tomography: their incidence, course, and characteristics. Oral Surg Oral Med Oral Pathol Oral Radiol 115:692-699

Patruban C (1865) Österreichische Zeitschrift für praktische Heilkunde. Herausgegeben vom doktoren-collegium der medicinishen facultät in Wien. IX Jahrgang, Wien
Paraskevas G, Mavrodi A, Natsis K (2015) Accessory mental foramen: an anatomical study on dry mandibles and review of the literature. Oral Maxillofac Surg 19:177-181

Phillips JL, Weller RN, Kulild JC (1992) The mental foramen: part II. Radiographic position in relation to mandibular second premolar. J Endod 18:271-274

Pocock RI (1914) On the facial vibrissae of mammalia. Proc Zool Soc Lond 84:889-912

Prabodha LBL, Nanayakkara BG (2006) The position, dimensions and morphological variations of mental foramen in mandibles. Galle Med J 11:13-15

Rai R, Shrestha S, Jha S (2014) Mental foramen: a morphological and morphometrical study. Int J Health Biomed Res 2:144-150

Rambaud A, Renault C (1864) Origine et développement desos. Atlas. fol, Paris

Ramirez KR (2019) Presence of two mandibular canals and distinction of the inferior alveolar and mental nerves proximal to the mandible: a case study. Transl Res Anat 14:6-8

Riesenfeld A (1956) Multiple infraorbital, ethmoidal, and mental foramina in the races of man. Am J Phys Anthropol 14:85-100

Robinson CA (2003) Extant hominoid and australopith mandibular morphology; assessing alpha taxonomy and phylogeny in hominoids using mandibular characters. Ph.D. Dissertation, New York University

Rusu MC, Săndulescu M, Ciuluvică RC et al (2011) The extramandibular inferior alveolar nerve in cases with severely atrophic lower jaws. Surg Radiol Anat 34(3):277-279

Santini A, Land MA (1990) Comparison of the position of the mental foramen in Chinese and British mandibles. Acta Anat 137:208-212

Santos O Jr, Pinheiro LR, Umetsubo OS et al (2013) Assessment of open source software for CBCT in detecting additional mental foramina. Braz Oral Res 27:128-135

Sawyer DR, Kiely ML, Pyle MA (1998) The frequency of accessory mental foramina in four ethnic groups. Arch Oral Biol 43:417-420

Schulz AH (1933) Chimpanzee fetuses. Am J Phys Anthropol 18:61-80

Schwartz DJ, Huelke DF (1963) Morphology of the head and neck of the macaque monkey: the muscles of mastication and the mandibular division of the trigeminal nerve. J Dent Res 42:1222-1233

Serman NH (1987) Differentiation of double mental foramina from extra bony coursing of the incisive branch of the mandibular nerve - an anatomic study. Refuat Hashinayim 5(3):20-22

Serres M (1819) Nouvelle Division des Apoplexies, Annuaire Med. Chirurg. Des Hop. Paris. Anat. Comp. du Cerveau t.II, Paris

Shelley AM, Rushton VE, Horner K (1999) Canalis sinuosis mimicking a periapical inflammatory lesion. Br Dent J 186:378-379

Simonton F (1923) Mental foramen in the anthropoids and in man. Am J Phys Anthropol 6:413-421

Singh R, Srivastav AK (2011) Evaluation of position, shape, size and incidence of mental foramen and accessory mental foramen in Indian adult human skulls. Int J Exp Clin Anat 5:23-29

Sisman Y, Sahman H, Sekerci AE et al (2012) Detection and characterization of the mandibular accessory buccal foramen using CT. Dentomaxillofac Rad 41:558-563

Soams RW (1995) Skeletal system. In: Williams PL, Bannister LH, Berry MM, Collins P, Dyson M, Dussek JE, Ferguson MWJ (eds) Gray's anatomy, 38th edn. Churchill Livingstone, New York, pp 576-578

Souaga K, Adou A, Angoh Y (2004) Topographical and morphological study of the mandibular foramen in black Africans from the Ivory Coast. Odontostomatol Trop 27(105):17-21 
Sunohara M, Miwa Y, Sato I (2017) A morphological study of the foramina of the mandible in the Japanese macaque by cone-beam computed tomography. Okijamas Folia Anat Jpn 93(4):153-158

Sutton RN (1974) The practical significance of mandibular accessory foramina. Aust Dent J 19:167-173

Swindler DR, Wood CD (1982) Atlas of primate gross anatomy. Robert E. Krieger Publishing Company, Malabar

Takai M, Anaya F, Shigehara N et al (2000) New fossil materials of the earliest new world monkey, Branisella boliviana, and the problem of platyrrhine origins. Am J Phys Anthropol 111(2):263-281

Thakur G, Thomas S, Thayil SC et al (2011) Accessory mental foramen: a rare anatomical finding. BMJ Case Rep 2011:bcr0920103326

The L, Wallace ML, Chen CH et al (2013) Structure, function, and cortical representation of the rat submandibular whisker trident. J Neurosci 33:4815-4824

Toh H, Kodama J, Yanagisako M et al (1992) Anatomical study of the accessory mental foramen and the distribution of its nerve. Okajimas Folia Anat Jpn 69:85-88

Torres MGG, Valverde LF, Vidal MTA et al (2015) Accessory mental foramen: a rare anatomical variation detected by cone-beam computed tomography. Imag Sci Dent 45:61-65

Turpin DL (1968) Growth and remodeling of the mandible in the Macaca mulatta monkey. Am J Orthod 54(4):251-271 von Arx T, Lozanoff S (2017) Clinical oral anatomy. A comprehensive review for dental practitioners and researchers. Springer International Publishing, Cham

von Arx T, Lozanoff S, Bosshardt D (2014) Accessory mental foramina: anatomy and histology of neurovascularisation in four cases with apical surgery. Oral Surg 7:216-227

Warwick R (1950) The relation of the direction of the mental foramen to the growth of the human mandible. J Anat 84(2):116-120

Weidenreich E (1936) The mandibles oi Sinanthropus pekinensis: a comparative study. Palaeontol Sin Ser D 7(3):1-162

Williams FL, Krovitz GE (2004) Ontogenetic migration of the mental foramen in Neandertals and modern humans. J Hum Evol 47:199-219

Won SY, Yang HM, Woo HS et al (2014) Neuroanastomosis and the innervation territory of the mental nerve. Clin Anat 27(4):598-602

Zivanovic S (1970) Some morphological characters of the East African mandible. Acta Anat 77:109-119

Publisher's Note Springer Nature remains neutral with regard to jurisdictional claims in published maps and institutional affiliations. 